\title{
Construction building systems protection under emergency exposure
}

\author{
Sergey Merkulov ${ }^{1}$, Natalya Polyakova ${ }^{1}$, Vladimir Rimshin ${ }^{2}$, Ekaterina Kuzina, ${ }^{3, *}$, and \\ Alexey $\mathrm{Neverov}^{3}$ \\ ${ }^{1}$ Kursk State University, 33, Radishcheva st., 305000, Kursk, Russia \\ ${ }^{2}$ Moscow State University of Civil Engineering, 26, Yaroslavskoye Shosse, 129337, Moscow, Russia \\ ${ }^{3}$ Research Institute of Building Physics of the Russian Academy of Architecture and Building \\ Sciences (NIISF RAASN), Lokomotivny Ave., 21, 127238, Moscow, Russia
}

\begin{abstract}
The structural reliability of the building ensures the building safety as a whole and the safety of the population, therefore the issue of ensuring reliability arises primarily in the design process. Buildings must be protected from destruction during all types of force, as well as in the case of load-bearing structures destruction as a result of emergency. Emergency impact on an object is an unregulated impact that is created as a result of an object getting into a special situation and can lead to its accident. The causes of structures progressive collapse are considered in this article. The main methods and methods of protecting buildings from progressive destruction are given. The calculation analysis of the monolithic reinforced concrete building frame for progressive collapse according to the method of possible damage is performed. There are many calculated and constructive proposals for solving the problems of counteracting the progressive destruction that can be divided into three categories: secondary protection measures, indirect design and direct design. In this article the resulting reinforcement of structural elements is determined taking into account the structural requirements for the continuity of longitudinal reinforcement, the minimum percentage of reinforcement. They are determined in the necessary places of additional reinforcement depending on the accepted permanent (background) reinforcement of the floors.
\end{abstract}

\section{Introduction}

The emergency impact on a building is in most cases always an emergency. In particular, these are:

- Natural emergencies. These include seismic impacts, hurricanes, tornadoes and other meteorological phenomena. Severe consequences are noted as a result of karst funnels formation and dips in the base of the buildings.

\footnotetext{
* Corresponding author: kkuzzina@mail.ru
} 
- Anthropogenic (including technogenic) emergency situations. The most serious consequences are noted in explosions and fires. In this case, there are explosions as a result of a terrorist act, improper operation of domestic gas and explosive gas mixtures and liquids.

One of the types of emergency is a traffic accident. This assumes a car colliding with a building and aircraft accidents. There are a number of other reasons contributing to an emergency: design errors, disruption of work, defects in prefabricated typical structures and low-quality material, negligence of residents and management companies when operating the building and equipment in it. In addition to the prescribed emergency situations, emergency actions include shock impacts, which in most cases also lead to severe emergency situations. Emergency shock loads on buildings and structures, as well as seismic and emergency explosive, are classified as special impacts, since they are characterized by high intensity and rare repeatability [1-3].

Impacts are typical for industrial facilities or buildings and structures under construction due to improper operation of construction cranes. A shock may occur, for example, during the construction of a multi-story building or a multistorey or high structure during an emergency break of the sling, with careless securing of the cargo, careless rotation of the crane arm, etc. [4-10].

Research methods: Options for ensuring constructive safety in case of emergency are worked out every year, however, many questions remain. Horizontal impacts are carried out by columns of garages, supports of industrial and transport overpasses, street lamp racks during collisions of vehicles, supports of bridges and berth structures in bulk ships, etc. [1115]. A progressive collapse may occur when some elements fail due to accidental impacts.

Methods of protection against progressive collapse is one of the most pressing topics among scientific researchers. The term «progressive collapse» refers to a situation where the destruction or structure damage leads to complete or almost complete destruction of the entire structure. The building stability against progressive destruction should be checked by calculation and provided with constructive measures.

\section{Materials and Methods}

All methods can be divided into three categories: secondary protection measures, indirect design and direct design.

Secondary protection measures are completely prevented or reduced the impact of events that cause emergency loads on the building or structure. These protection methods are achieved by the introduction of special protective equipment, for example, the installation of gaps or safe distances, when placing potential dangerous targets and critical points (structural units) that may be vulnerable.

The means and methods of secondary protection of the building also include architectural and planning security elements; localization of the building from crowded places; special coloring of the surface, which increases resistance to fire or explosive action; checkpoint; reduction in the number of access points; observation posts; control out of the perimeter, etc.

These measures are economically acceptable ways to protect the building from collapse, but do not increase the durability of the structure. To provide resistance to progressive destruction, they can be considered as additional protection against emergency situations. The method of indirect design is determined on the minimum requirements for the buildings and structures that provide protection against progressive collapse.

They rely on the term "general structural integrity» M. Fintel and, analyzing the rules for designing US standards, identify the main requirements that increase the resistance of structures in [20] for describing this method: good building plan; a complete 
communications system; changes in the directions of spans in the ceilings; distribution of internal load-bearing elements; use of a hanging system in ceilings; the action of the walls as beams; systems with excessive static indeterminacy; additional fittings for the perception of shock explosive loads; structures insulation.

The principle is clear - it is necessary that the design has a natural resistance to any influences of the design level. The durability of the structure against progressive collapse in this method is not specifically determined.

The direct design method considers alternative ways of loading structures after local damage and subsequent destruction, and local resistance in the load-bearing elements of the building.

The alternative resistance method is aimed at maintaining the bearing capacity of the structure after the loss of the structural element and the localization of destruction. This method is also called the «bridge» method, because the loads of elements that have lost support must go to other elements (columns, walls, beams) over some «bridge».

The design scheme is designed in such a way as to compensate for the loss of the bearing element of the building by redistributing the forces and localize the damage zone. Set the minimum allowable area and volume of local destruction. If adjacent elements are strong enough to distribute the load, it will be possible to evacuate people in the building.

The method of assigning local resistance is to ensure the resistance of parts of the building to special loads and influences. It is assumed that key elements are calculated for some sudden impact of common loads applied to the elements together (for example, pressure from a blast wave). The last method is divided into two types:

- method of local resistance;

- method of possible damage.

In the local resistance method, critical elements are provided with sufficient resistance calculated for a predetermined extreme load. Each structural element in the system that is not able to work according to the «bridge» scheme is designed as a «key» or «protective» one, capable of perceiving emergency influences. The disadvantage of the local resistance method is that the magnitude of the emergency load and the impact area must be known, which is difficult to calculate.

In addition to the above-described methods of protection against progressive destruction, mainly associated with an increase in the strength of individual elements and their knots of their conjugation, structures as a whole by enhancing connectivity and continuity, the opposite approaches have also been developed, called «segmentation» [2031 ], or the method controlled collapse.

\section{$3 \quad$ Results}

The essence of the approach is based on the principle of limiting the collapse of the structure as a whole by dividing it into separate independent or weakly interconnected independent substructures, each of which has its own structural system to ensure strength and stability [15-20].

In case of a sudden emergency impact on the supporting element of the substructure, the largest area of possible destruction remains within the boundaries of the substructure, the impact on adjacent substructures is completely limited.

To limit the magnitude of possible destruction, expansion joints are provided between segments of several adjacent spans, constructing each segment as a separate structural unit [24-31]. In the vertical direction, communication floors or powerful crossbars of interfloor ceilings are arranged [20-25].

In $[5,6]$ it was shown that the use of transition floors, which allow isolating damage zones, is the most economical and reliable. It is this technique that has been applied in some 
buildings of Moscow City in the form of a system of 5-10-story frame blocks above the communication floor. So, in the «Burj Khalifa» building in the UAE, up to 20 floors are «suspended» to the communication unit.

It is accepted that every 15-20 floors of a high-rise system, the building is divided by one transitional floor in the form of a continuous structure: a truss, cross connections, trellised beam, etc. Such transitional floors delimit the building stiffness in height, with each part of the building between these floors work independently. If local collapse occurs inside such compartments, then collapse or deformation of structures below and above this compartment does not spread.

The above methods and methods of protecting buildings and structures from progressive destruction can be applied both individually and in combination with each other.

The Russian standards and recommendations propose an additional strength method. Extra strength is realized using safety factors for responsibility. All structural elements are designed with a margin of up to $120 \%$.

Nowadays the most common method is the method of possible damage.

According to this method, the behavior of the system is analyzed in detail after turning off an element from the operation.

The main idea of the method is as follows: when one of the several load-bearing elements is destroyed, the remaining part of the structure must be able to withstand the loads acting on it. Thus, it is possible to prevent or slow down the process of progressive destruction. According to this method, it is necessary to suddenly remove one bearing element and calculate the rest of the building so that it does not collapse. So the work of the damaged structure is subjected to detailed analysis, while the cause of local destruction is not necessary to know.

According to normative documents structural systems calculation should be done separately for each (one) local destruction to prevent progressive collapse.

It is allowed to calculate only the most dangerous cases of destruction, which may be schemes with the destruction of alternately vertical load-bearing structural elements: having the largest cargo area; located at the edge of the ceiling; located in the corner; and disseminate the results of these calculations to other sections of the structural system.

Such a calculation should theoretically be carried out with the removal of all the columns, but in most cases it is enough to consider a limited number of defining situations and to extend the results of this consideration to other parts of the structures.

The «progressive destruction» mode implemented in the SCAD complex is designed to model the behavior of the buildings and structures in the event of emergency actions that cause local destruction of individual vertical load-bearing elements.

The structural scheme of the building of a shopping and office center of variable height is considered as an example of calculating the progressive destruction by the method of possible damage.

The building has a complex shape with a total size of $32.00 \times 40.00 \mathrm{~m}$ according to the configuration in the plan. The largest number of aboveground floors is 8 , underground floor is 1 .

The building structural scheme of the shopping and office center adopted frame. The framework is monolithic and reinforced concrete, consisting of columns, vertical stiffness diaphragms and vertical monolithic walls of stairs and elevators. Horizontal elements of the frame are monolithic floor beams and monolithic floor slabs. The overall stability and immutability of the frame is ensured by a rigid connection of monolithic reinforced concrete columns with monolithic reinforced concrete beams and floor slabs. Additional frame rigidity is provided by monolithic vertical reinforced concrete diaphragms and walls. 
The frame structures are designed for the perception of vertical and horizontal loads acting on the building. Horizontal loads include wind loads; vertical loads include loads from the dead weight of structures, snow and temporary loads on floors.

For the progressive destruction calculation, we take the uncertainty coefficient of $15 \%$ and $50 \%$. The calculation is performed taking into account geometric nonlinearity by a simple step-by-step method. The steps number is 5 .

\section{Discussion}

The building frame was calculated on the main combination of loads for the operation stage (primary structural system) and on a special combination of loads to prevent progressive collapse (secondary structural systems). The primary structural system is a system that is designed for the normal operation of the building, under the conditions provided for normative documents. Secondary structural systems of a building is a primary structural system, changed by the sudden removal of one vertical supporting structural element within the same floor.

Cases of alternately bearing elements exclusion are considered when calculating the secondary structural system:

- middle column № 1 on the 1st floor;

- the extreme column № 2 on the 1st floor;

- Angular column № 3 on the 1st floor (see Figure 1).

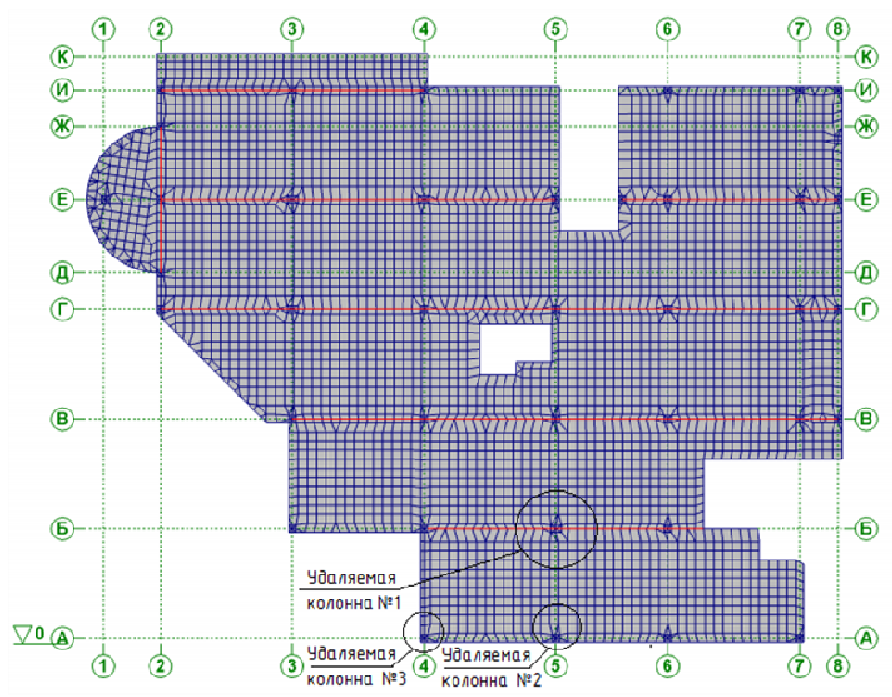

Fig. 1. Settlement scheme of the building at 0,000

Progressive fracture test results are displayed graphically on a three-color scale. Elements of the circuit are divided by color into working (with a utilization factor $K$

$K_{\max }<1$ ), painted in green, out of order is red. Elements that fall into the uncertainty interval are indicated in yellow (see Figure 2). 


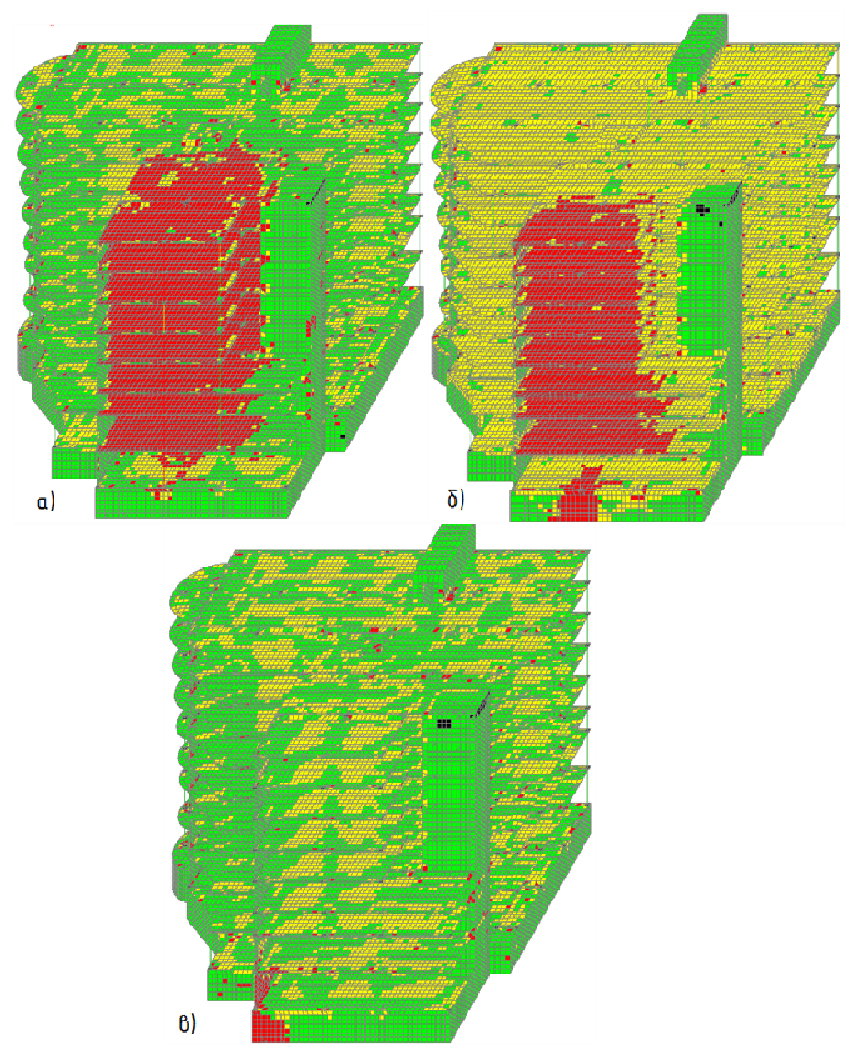

Fig. 2. Color separation according to strength, taking into account the uncertainty interval: a) the columns № 1 destruction; b) the column № 2 destruction; c) the column № 3 destruction.

The reinforcement of a certain position prevails when selecting reinforcement according to the results of strength analysis in the sections. So, in the spans the lower reinforcement most often prevails, and on the supports the upper reinforcement. The nature of the stressstrain state of the element can change as a result of the destruction of the supporting structures. The support zones of the ceilings and beams adjacent to the failed column become span. In this case, it is necessary to set the initial reinforcement, which should not be smaller in cross section.

Reinforcement is specified by the value of the reinforcement area for each type (longitudinal - lower, upper, lateral; transverse - along different section faces), for each section or for each plate element. The initial reinforcement is always the same for all elements in the same group.

The calculation results for a given minimum reinforcement are given in Figure 3. The calculation was performed by a simple step-by-step method taking into account geometric nonlinearity. 


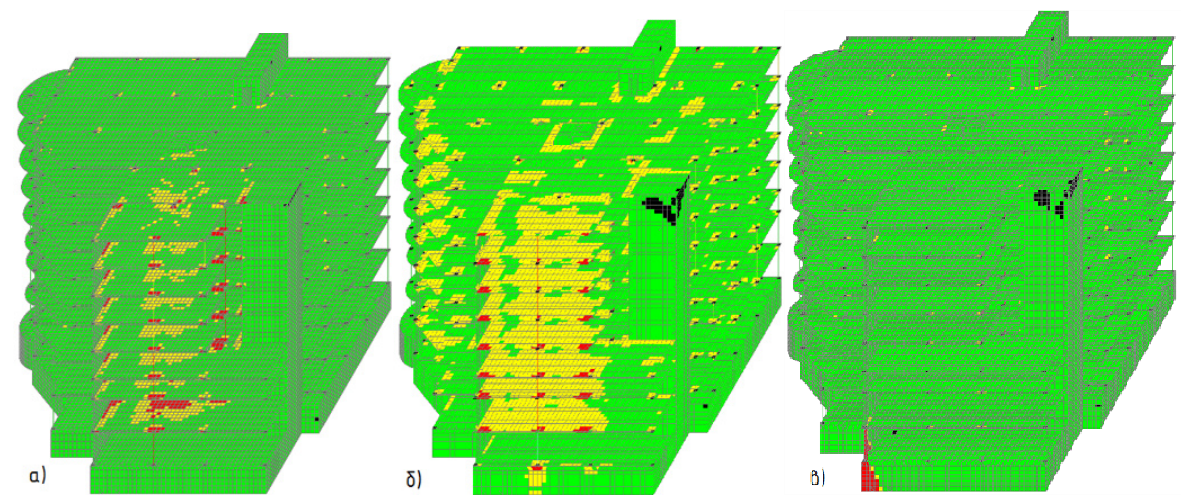

Figure 3. Color separation by strength, taking into account the uncertainty interval for a given minimum reinforcement: a) the columns № 1 destruction; b) the column № 2 destruction; c) the column № 3 destruction.

\section{Conclusions}

As a result of the primary and secondary structural systems calculation, the resulting reinforcement of structural elements is determined taking into account the structural requirements for the continuity of longitudinal reinforcement, the minimum percentage of reinforcement. They are determined in the necessary places of additional reinforcement depending on the accepted permanent (background) reinforcement of the floors.

It can be drawn some conclusions after analyzing the results:

- in most cases, the removal of one of the supporting structures leads to overloading of neighboring structures, thereby causing an increase in stresses, exceeding their bearing capacity;

- the main and the simplest method for protecting buildings and structures from progressive destruction is to reserve the strength of load-bearing structures;

- redundancy of the vertical and horizontal load-bearing structures strength is achieved by installing additional reinforcement, taking into account the structural requirements for the continuity of longitudinal reinforcement, assigning a minimum percentage of reinforcement.

\section{References}

1. S.I. Merkulov, A.I. Tatarenkov, R.V. Lesovik, International Conference on Actual Issues of Mechanical Engineering (AIME). AER-Advances in Engineering Research 133, 409-413 (2017)

2. A.L. Krishan, V.I. Rimshin, E.A. Troshkina, IOP Conference Series: Materials Science and Engineering, 463 (2), 022062 (2018)

3. A.L. Krishan, M.Yu Narkevich,. A.I. Sagadatov, V.I. Rimshin, IOP Conference Series: Materials Science and Engineering 456 (1), 012049 (2018)

4. V. Telichenko, V. Rimshin, E. Kuzina, MATEC Web of Conferences 251, 04061 (2018)

5. V. Telichenko, V. Rimshin, V. Eremeev, V. Kurbatov, MATEC Web of Conferences 196, 02025 (2018)

6. A.A. Varlamov, V.I. Rimshin, S.Y. Tverskoi, IOP Conference Series: Earth and Environmental Science 177 (1), 012040 (2018)

7. V.I. Rimshin, B.V. Labudin, V.I. Melekhov, A. Orlov, V.L. Kurbatov, ARPN Journal of Engineering and Applied Sciences 13 (11), 3851-3856 (2018) 
8. V.I. Rimshin, A.A. Varlamov, (2018) News of Higher Educational Establishments, Series Technology Textile Industries 3, 63-68 (2018)

9. V.I. Rimshin, A.A. Pudova, L.I. Shubin, News of Higher Educational Establishments, Series Technology Textile Industries 3, 287-293 (2018)

10. A.A. Varlamov, V.I. Rimshin, S.Y Tverskoi, IFAC-PapersOnLine 51(30), 808-811 (2018)

11. E. Kuzina, V. Rimshin, Advances in Intelligent Systems and Computing 692, 410-416 (2018)

12. V. Rimshin, R. Aralov, E3S Web of Conferences 110, 01011 (2019)

13. E. Kuzina, V. Rimshin, E3S Web of Conference 97, 04007 (2019)

14. E. Kuzina, V. Rimshin, Advances in Intelligent Systems and Computing 983, 911-919 (2019)

15. A. Varlamov, V. Rimshin, S. Tverskoi, E3S Web of Conferences 91, 02046 (2019)

16. V. Rimshin, B. Labudin, V. Morozov, A. Orlov, A. Kazarian, V. Kazaryan, Advances in Intelligent Systems and Computing 983, 867-876 (2019)

17. E. Kuzina, V. Rimshin, V. Kurbatov, IOP Conference Series: Materials Science and Engineering 463(4), 042009 (2018)

18. N.I. Karpenko, V.A. Eryshev, V.I. Rimshin, IOP Conference Series: Materials Science and Engineering 463(3), 032024 (2018)

19. A.A. Varlamov, V.I. Rimshin, S.Y. Tverskoi, IOP Conference Series: Materials Science and Engineering 463(2), 022029 (2018)

20. A.L. Krishan, V.I. Rimshin, M.A. Astafeva, IOP Conference Series: Materials Science and Engineering 463(2), 022063 (2018)

21. A.A. Varlamov, V.I. Rimshin, S.Y. Tverskoi, IOP Conference Series: Materials Science and Engineering 463(2), 022028 (2018)

22. E. Kuzina, A. Cherkas, V. Rimshin, IOP Conference Series: Materials Science and Engineering 365(3), 032053 (2018)

23. A. Cherkas, V. Rimshin, MATEC Web of Conferences 117, 00027 (2017)

24. V.I. Telichenko, V.I. Rimshin, A.V. Karelskii, B.V. Labudin, V.L. Kurbatov, Journal of Industrial Pollution Control 33(1), 1034-1041 (2017)

25. A.L. Krishan, V.L. Rimshin, V.A. Rakhmanov, E.A. Troshkina, V.E. Kurbatov, News of Higher Educational Establishments, Series Technology Textile Industries 370(4), 220-225 (2017)

26. A.L. Krishan, V.I. Rimshin, V.I. Telichenko, V.A. Rakhmanov, M.Yu. Narkevich, News of Higher Educational Establishments, Series Technology Textile Industries 2, 227-232 (2017)

27. I.L. Shubin, Y.V. Zaitsev, V.I. Rimshin, V.L. Kurbatov, P.S. Sultygova, Engineering Solid Mechanics 5(2), 139-144 (2017)

28. S.A. Korotaev, V.I. Kalashnikov, V.I. Rimshin, I.V. Erofeeva, V.L. Kurbatov, Ecology, Environment and Conservation 22(3), 1159-1164 (2016)

29. A.L. Krishan, E.A. Troshkina, V.I. Rimshin, V.A. Rahmanov, V.L. Kurbatov, Research Journal of Pharmaceutical, Biological and Chemical Sciences 7(3), 2518-2529 (2016)

30. V.T. Erofeev, E.V Zavalishin,.V.I. Rimshin, V.L. Kurbatov, M.B. Stepanovich, Research Journal of Pharmaceutical, Biological and Chemical Sciences 7(3), 2506-2517 (2016)

31. Y.M. Bazhenov, V.T. Erofeev, V.I. Rimshin, S.V. Markov, V.L. Kurbatov, Engineering Solid Mechanics 4(4), 219-225 (2016) 